\title{
MicroRNA-27b functions as a new inhibitor of ovarian cancer-mediated vasculogenic mimicry through suppression of VE-cadherin expression
}

\author{
WENMING LIU, CHUNPING LV, BIN ZHANG, QUANSHENG ZHOU, and ZHIFEI CAO \\ Cyrus Tang Hematology Center, Jiangsu Institute of Hematology, 2011 Collaborative Innovation Center of Hematology, Key Laboratory of Thrombosis \\ and Hemostasis, Ministry of Health, Key Laboratory of Stem Cells and Biomedical Materials of Jiangsu Province, and Chinese Ministry of Science and \\ Technology, Soochow University, Suzhou, Jiangsu 215123, P.R. China
}

\begin{abstract}
Aggressive cancer cells gain robust tumor vascular mimicry (VM) capability that promotes tumor growth and metastasis. VEcadherin is aberrantly overexpressed in vasculogenic cancer cells and regarded as a master gene of tumor VM. Although microRNAs (miRNAs) play an important role in modulating tumor angiogenesis and cancer metastasis, the miRNA that targets $V E$-cadherin expression in cancer cells to inhibit tumor cell-mediated VM is enigmatic. In this study, we found that miR-27b levels are negatively co-related to VE-cadherin expression in ovarian cancer cells and tumor cell-mediated VM, and demonstrated that miR-27b could bind to the $3^{\prime}$-untranslated region ( $\left.3^{\prime} U T R\right)$ of $V E$-cadherin mRNA. Overexpression of miR27b in aggressive ovarian cancer cell lines Hey1B and ES2 significantly diminished intracellular VE-cadherin expression; convincingly, the inhibitory effect of miR-27b could be reversed by miR-27b specific inhibitor. Intriguingly, miR-27b not only effectively suppressed ovarian cancer cell migration and invasion, but also markedly inhibited formation of ovarian cancer cell-mediated capillary-like structures in vitro and suppressed generation of functional tumor blood vessels in mice. Together, our study suggests that miR-27b functions as a new inhibitor of ovarian cancer cell-mediated VM through suppression of $V E$ cadherin expression, providing a new potential drug candidate for antitumor VM and anti-ovarian cancer therapy.
\end{abstract}

Keywords: ovarian cancer; miR-27b; VE-cadherin; vasculogenic mimicry

\section{INTRODUCTION}

Ovarian cancer is the foremost cancer that threatens the life of women worldwide (da Costa et al. 2016; Davidson 2016). Although great effort has been made in the treatment of ovarian cancer, including surgical radical resection, chemotherapy, and radiotherapy, the 5-yr survival rate of patients is only 35\% (Suh-Burgmann and Kinney 2016); hence, new strategies and therapeutics are highly desired to keep ovarian cancer at bay. Malignant tumors usually have a robust angiogenesis (Folkman 1971; Carmeliet and Jain 2011) and vasculogenic mimicry (VM) (Hendrix et al. 2001; Cao et al. 2013a,b). Accumulated evidence shows that tumor cell-mediated VM increases the progression and metastasis of various malignant tumors (Cao et al. 2013a, b), including ovarian cancer ( $\mathrm{Du}$ et al. 2014), lung cancer (Wu et al. 2012), breast cancer (Fry et al. 2016), gastric cancer (Li et al. 2010), colon cancer (Baeten et al. 2009), osteosarcoma cancer (Ren et al. 2014), pancreatic cancer (Xu et al.

Corresponding authors: zhfcao@suda.edu.cn, zhouqs@suda.edu.cn Article is online at http://www.rnajournal.org/cgi/doi/10.1261/rna.059592. 116.
2014), and glioma (Mao et al. 2013); notably, cancer celllined vascular channels supply oxygen and nutrition for tumor growth and cancer cell metastasis (Cao et al. 2013a, b; Wagenblast et al. 2015). Additionally, tumor VM is corelated to metastatic tumors and closely associated with poor prognosis of cancer patients (Cao et al. 2013b; Wagenblast et al. 2015). Accordingly, tumor VM has been regarded as a sensible target for anticancer therapy (Hendrix et al. 2016; Tang et al. 2016); however, effective antitumor VM therapeutics is absent in the clinical setting and highly desired.

Multiple genes are involved in tumor VM. Among the important genes that increase VM, vascular endothelial cadherin (VE-cadherin or CDH5) is recognized as a master gene of tumor VM (Hendrix et al. 2001; Seftor et al. 2012; Cao et al. 2013a,b; Mao et al. 2013). VE-cadherin is a cell surface adherent protein that connects the cancer cells with its

(C) 2017 Liu et al. This article is distributed exclusively by the RNA Society for the first 12 months after the full-issue publication date (see http:// rnajournal.cshlp.org/site/misc/terms.xhtml). After 12 months, it is available under a Creative Commons License (Attribution-NonCommercial 4.0 International), as described at http://creativecommons.org/licenses/by-nc/4.0/. 
extracellular domains to form tumor blood vessels (Hendrix et al. 2001; Seftor et al. 2012; Cao et al. 2013b,c; Mao et al. 2013). In normal tissues and cells, VE-cadherin is restrictively expressed in vascular endothelial cells, not in various other normal tissues and cells; however, it is aberrantly overexpressed in various malignant tumors (Hendrix et al. 2001, 2016; Seftor et al. 2012; Cao et al. 2013b,c; Mao et al. 2013). Convincingly, either blocking the cell membrane surface $V E$-cadherin with a specific antibody against the protein (May et al. 2005), or down-regulation of VE-cadherin gene expression by small molecules, results in diminishing the neovascularization of malignant tumors including ovarian cancer (Bao et al. 2012; Cao et al. 2013c; Liu et al. 2015c; Tang et al. 2016). Hence, tumor cell VE-cadherin has been selected as a target for novel antitumor vasculogenic and anticancerous drug discovery.

MicroRNAs (miRNAs) are small noncoding RNAs consisting of 19-24 nucleotides (nt), acting as the crucial posttranscriptional regulators of gene expression through specific binding to target mRNA (Yang et al. 2005). Although various miRNAs have recently been found to play an important role in the regulation of endothelial cell-mediated tumor angiogenesis (Khorshidi et al. 2016; Wang et al. 2016), the miRNAs that can inhibit tumor cell-dominant VM through targeting VE-cadherin in cancer cells have not been fully understood yet. Among the miR-27 family, miR-27a has been reported to inhibit VE-cadherin expression, EMT (Zhao et al. 2016), and miR-27b reduced endothelial cell-mediated angiogenesis (Young et al. 2013); however, whether miR-27b suppresses tumor cell-mediated VM by diminishing the $V E$-cadherin expression level in ovarian cancer has not been addressed at present.

In the current study, we found that the low expression levels of miR-27b were not only closely associated with high VE-cadherin gene expression, but also with the strong VM capability of ovarian cancer cells, and we demonstrated that miR-27b directly bound to the $3^{\prime} \mathrm{UTR}$ of VE-cadherin mRNA. Convincingly, miR-27b mimics significantly downregulated $V E$-cadherin expression and effectively inhibited ovarian cancer cell VM migration, invasion in vitro, and formation of functional blood vessels in mice with ovarian cancer cells-xenograft, and it provided a miRNA-based new therapeutic candidate for antitumor VM and anti-ovarian cancer therapy.

\section{RESULTS}

\section{Low miR-27b expression levels are closely associated with high VE-cadherin expression and the robust vasculogenic mimicry capability of ovarian cancer cells}

It is well established that VE-cadherin plays a critical role in tumor cell-mediated VM (Hendrix et al. 2001, 2016; Seftor et al. 2012; Cao et al. 2013b,c; Mao et al. 2013), and that miRNAs actively regulate tumor neovascularization
(Khorshidi et al. 2016; Wang et al. 2016); whereas whether miRNAs are able to modulate VE-cadherin expression in cancer cells and consequently affect tumor cell-dominant VM is largely unknown. In this study, we first searched for complementary miRNAs to VE-cadherin mRNA in the mRNA database using TargetScan Human v6.2 (http://www. targetscan.org), and we predicted a possible binding of miRNA-27b to the $3^{\prime} U T R$ of VE-cadherin mRNA (context + score percentile: 88 ; $\mathrm{P}_{\mathrm{CT}}$ : 0.87 ) based on the following sequence (UUGAA and UGACACUU) present in miRNA$27 \mathrm{~b}$ that is complementary to the $3^{\prime} \mathrm{UTR}$ of VE-cadherin mRNA (Fig. 1A). Further database and literature searches indicated that the effect of miRNA-27b on VE-cadherin expression in cancer cells and tumor cell-mediated VM have not been reported yet.
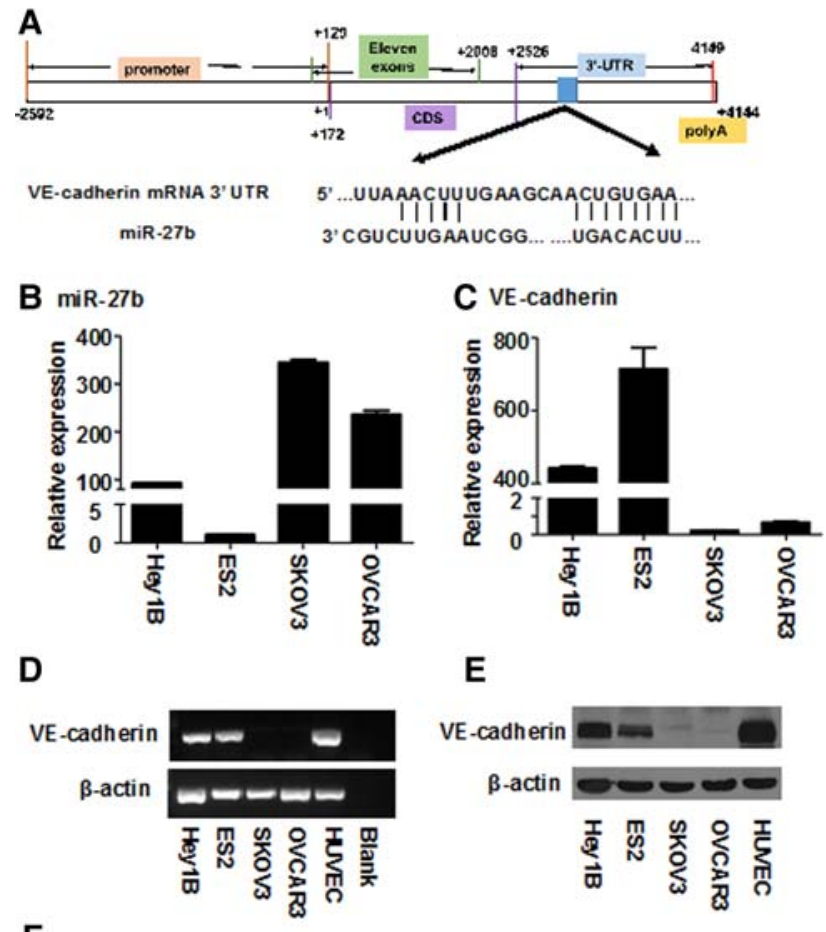

E

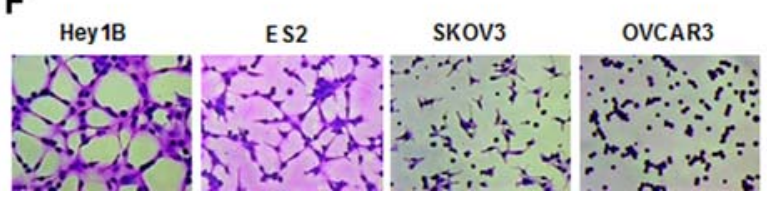

FIGURE 1. Low miR-27b levels are closely associated with high VEcadherin expression and robust vasculogenic mimicry capability of ovarian cancer cells. (A) The binding of miR-27b to the $3^{\prime} \mathrm{UTR}$ of VE-cadherin mRNA was analyzed using TargetScan Human v6.2. (B) Expression of miR-27b in four ovarian cancer cell lines (Hey1B, ES2, SKOV3, OVCAR3) was measured by real-time quantitative PCR (QTPCR). The expression of VE-cadherin in the four ovarian cancer cell lines was analyzed by QT-PCR $(C)$, RT-PCR $(D)$, and Western blotting $(E)$, respectively. $(F)$ The vasculogenic capabilities of the four ovarian cancer cell lines were subjected to a tube formation assay on Matrigel in vitro, and the capillary-like structures were stained with Giemsa solution and photographed by an inverted microscope. Results represent the mean of three individual experiments; error bars represent SD. 
Then, we experimentally measured the expression levels of both miRNA-27b and VE-cadherin in four ovarian cancer cell lines including Hey1B, ES2, SKOV3, and OVCAR3 using quantitative real-time PCR (QT-PCR), and found that the expression levels of miR-27b in low metastatic SKOV3 and OVCAR3 cells were 6.27 -fold higher than the two high metastatic ovarian cancer cell lines Hey1B and ES2 cells on average (Fig. 1B). In contrast, QT-PCR data (Fig. 1C) showed that the expression levels of VE-cadherin in miRNA-27boverexpressed SKOV3 and OVCAR3 were 267.36-fold less as compared to the Hey1B and ES2 cells expressed in low miRNA-27b. In addition, these results were also confirmed by RT-PCR (Fig. 1D) and Western blotting (Fig. 1E). In short, these results clearly indicate that there is a negative correlation between intracellular miRNA-27b amounts and VE-cadherin expression levels in ovarian cancer cells.

Convincingly, in vitro tube formation assay showed that Hey1B and ES2 cells, which have low miRNA-27b amounts but high VE-cadherin expression levels, directly formed capillary-like structures on the Matrigel even in the absence of vasculogenic growth factor supplement; whereas SKOV3 and OVCAR3 cells, which overexpressed endogenous miRNA-27b and barely expressed VE-cadherin, could not form capillary-like structures (Fig. 1F). Collectively, these data suggest that miR-27b levels are negatively co-related to both VE-cadherin expression and the VM capability of the ovarian cancer cells.

\section{MiR-27b targets the VE-cadherin mRNA $3^{\prime}$ UTR to suppress expression of the protein in ovarian cancer cells}

In light of the reverse correlation between miR-27b and VEcadherin expression levels in ovarian cancer cells, we performed a series of experiments to confirm the direct effect of miR-27b on VE-cadherin expression in ovarian cancer. Either a wild-type or mutant VE-cadherin mRNA 3'UTR (182 bp) that contains a predicted miR-27b binding site (position 715-722 at VE-cadherin mRNA $3^{\prime} \mathrm{UTR}$ ) was cloned into a psiCHECK-2 transcriptional reporter vector (Fig. $2 \mathrm{~A})$. Hey1B cells were transiently cotransfected with the reporter constructs together with either miR-27b mimics or scrambled miR-27b (smiR-27b). The luciferase assay showed that miR-27b mimics significantly attenuated the luciferase activity in the cells transfected with the wild-type VE-cadherin mRNA 3'UTR-psiCHECK-2 transcriptional reporter vector; whereas the luciferase activity was not changed in the cells cotransfected with either mutant VE-cadherin mRNA 3'UTR, which abolished miR-27b binding sites, or scrambled miR-27b, which lost the binding capability to VE-cadherin mRNA 3'UTR (Fig. 2B). Convincingly, after blockage of miR-27b by the miR-27b inhibitor, the luciferase activity in ovarian cancer cells did not significantly change (Fig. 2C). These data suggest that miR-27b may directly bind to VE-cadherin mRNA $3^{\prime} \mathrm{UTR}$ in the ovarian cells.

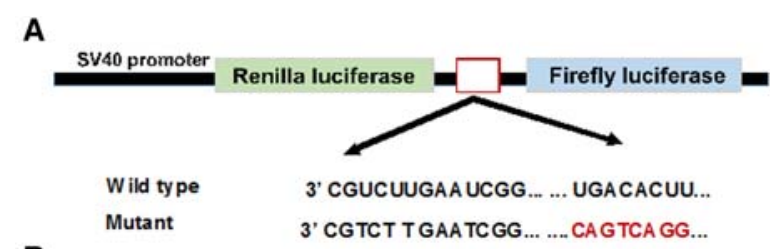

B
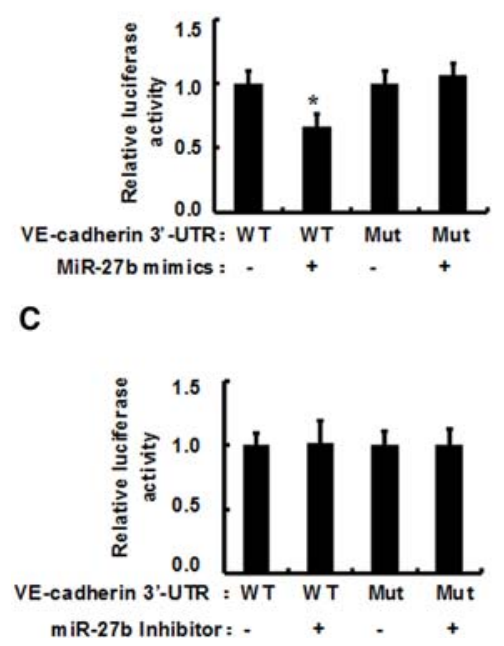

FIGURE 2. MiR-27b targets VE-cadherin $3^{\prime}$ UTR mRNA in ovarian cancer cells. 182 bp of either a wild-type or mutant VE-cadherin mRNA 3'UTR that contains a predicted miR-27b binding site (red color) were cloned into psiCHECK-2 transcriptional reporter vector $(A)$ and were transiently cotransfected with the reporter constructs together with either miR-27b mimics or scrambled miR-27b (smiR-27-b). After $2 \mathrm{~d}$ of transfection, the luciferase activity was measured $(B)$. Additionally, the wild-type or mutant-type of VE-cadherin $3^{\prime} \mathrm{UTR}$ reporter constructs was transiently cotransfected with either miR-27b inhibitor or scrambled miR-27b inhibitor, and the luciferase activity was detected $(C)$. Results represent the mean of three individual experiments; error bars represent SD. $\left({ }^{*}\right) P<0.05$ versus control.

Next, we investigated the effect of miR-27b on VE-cadherin expression in metastatic ovarian cell lines Hey1B and ES2 by transfection of the cells with miR-27b mimics and scrambled miR-27b, respectively. QT-PCR showed that miR-27b levels are markedly high after transfection of the mimics (Fig. 3A); whereas VE-cadherin expression levels were significantly reduced in the HeylB and ES2 cells transfected by miR-27b mimics when compared with the cells transfected by scrambled miR-27b (Fig. 3B). Similarly, Western blotting also indicated that the VE-cadherin protein levels were significantly decreased in miR-27b transfected cells compared to the cells transfected with the scrambled miR-27b control (Fig. 3C, D). Together, these data imply that miR-27b inhibits VE-cadherin expression in the aggressive ovarian cells.

\section{MiR-27b effectively suppresses ovarian cancer cell migration and invasion as well as vasculogenic mimicry}

Tumor cell migration and invasion play important roles in tumor cell-mediated VM and cancer metastasis (Cao et al. 
A

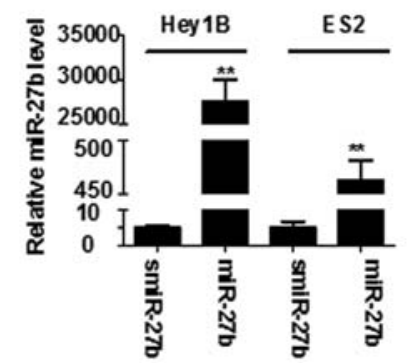

C

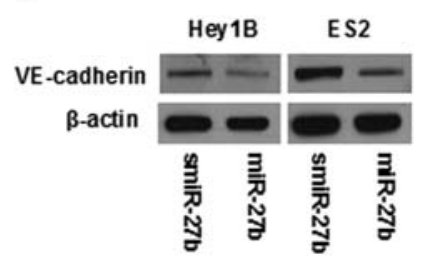

B

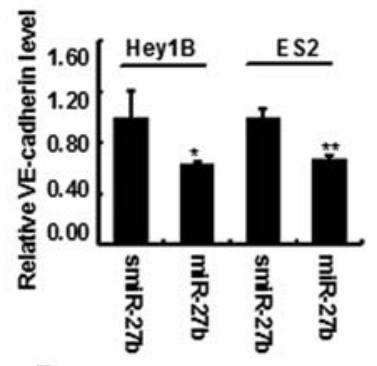

D

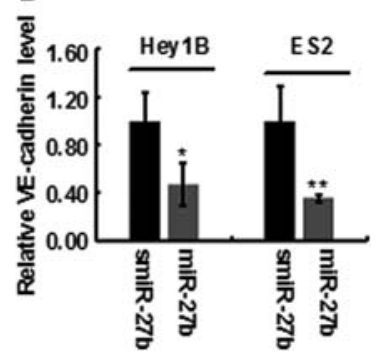

FIGURE 3. MiR-27b suppresses the VE-cadherin expression in ovarian cancer cells. After ovarian cancer cell lines (Hey1B and ES2) were transfected with miR-27b mimics or scrambled miR-27b (smiR-27-b), the expression of miR-27b $(A)$ and VE-cadherin $(B)$ was detected by QTPCR, respectively. The expression of VE-cadherin was also confirmed by Western blotting $(C)$. The bands were scanned and the results were statistically analyzed $(D)$. Results represent the mean of three individual experiments; error bars represent SD. $\left(^{*}\right) P<0.05$, (**) $P<0.01$ versus control.

2013b,c; Wagenblast et al. 2015); therefore, we investigated whether miR-27b can suppress the migration and invasion as well as VM of ovarian cancer cells. As shown in Figure $4 \mathrm{~A}$ and $\mathrm{B}$, the migration rate of HeylB cells overexpressing miR-27b was significantly lower than that of the control cells transfected with scrambled miR-27b. Similar results were also seen in another ovarian cancer cell line, ES2 (Fig. 4C, D). In addition, after expression of miR-27b, the invasive capability of ovarian cancer cells was significantly inhibited in both high metastatic ovarian cancer HeylB and ES2 cells (Fig. 4E,F), suggesting that miR-27b decreases ovarian cancer cell migration and invasion.

Subsequently, we investigated whether miR-27b could inhibit ovarian cancer cell-mediated VM. In vitro tube formation assay showed that overexpression of miR-27b in HeylB and ES2 cells strongly inhibited the formation of capillarylike structures (Fig. 5A,B), suggesting that miR-27b diminishes the VM capability of ovarian cells. Furthermore, we used a standard Matrigel-plug model to detect whether miR-27b suppresses formation of blood vessels by HeylB cells in mice. Tissue hematoxylin and eosin (HE) staining indicated that the density of ovarian cell-lined functional blood vessels was high in the tumor tissues from the mice transplanted with scrambled miR-27b-transfected HeylB cells; whereas the blood vessel density was much lower in the tumor tissues from mice transplanted with miR-27b-transfect-

ed Hey1B cells (Fig. 5C,D). In addition, in the tumor tissues, $V E$-cadherin expression was obviously inhibited in the ovarian cancer cells transfected by miR-27b as compared to the scrambled miR-27b control (Fig. 5E), which was consistent with the antivasculogenic effect of miR-27b in vitro as mentioned above (Fig. 3C,D). Collectively, these results indicate that miR-27b effectively inhibits ovarian cancer VM in vivo.

Taken together, low miR-27b expression levels are closely associated with high VE-cadherin expression and the robust vasculogenic mimicry capability of ovarian cancer cells. MiR-27b binds to the $3^{\prime} \mathrm{UTR}$ of VE-cadherin mRNA to diminish intracellular VE-cadherin expression in aggressive ovarian cancer Hey1B and ES2 cells, suppresses ovarian cancer cell migration and invasion, and inhibits ovarian cancer

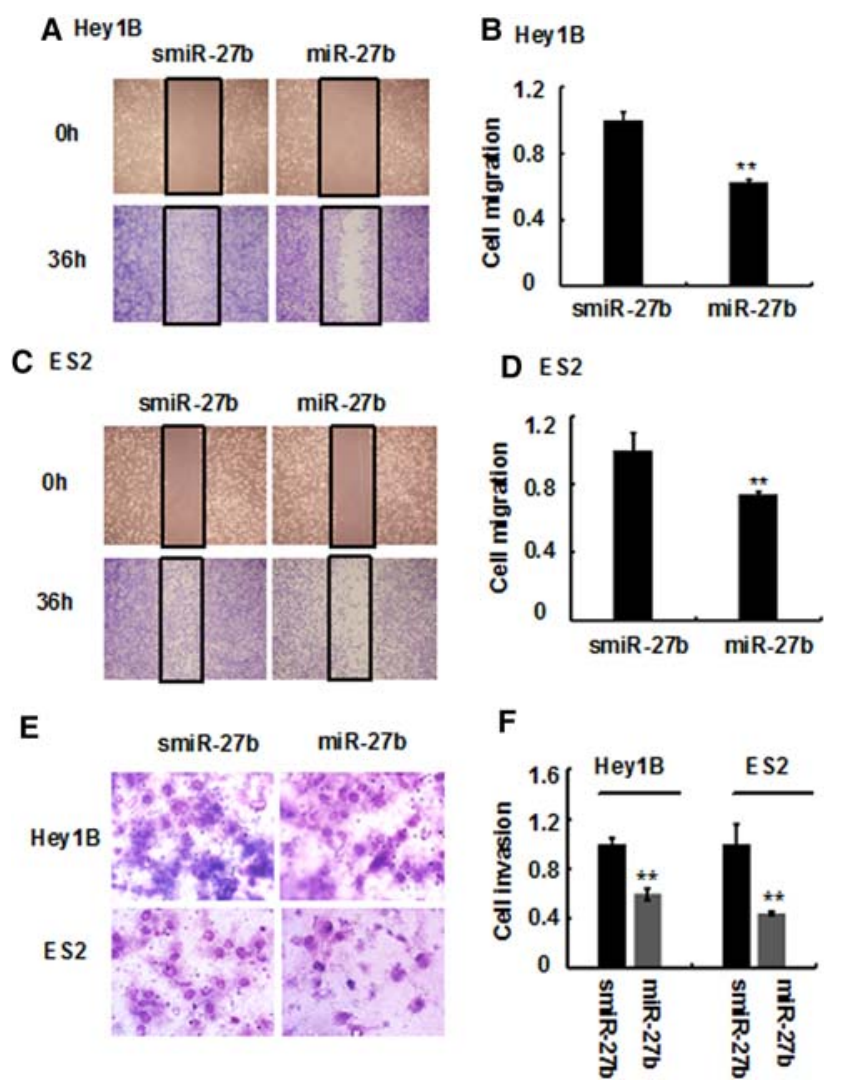

FIGURE 4. MiR-27b diminishes ovarian cancer cell migration and invasion. Ovarian cancer cell lines (Hey1B and ES2) were transfected with miR-27b mimics or scrambled miR-27b (smiR-27-b), and the cells were plated in six-well plates. When the cells formed a confluent monolayer, it was first scraped with the fine end of a pipette tip; then the migrated cells were counted and imaged under an OLYMPUS FSX-100 microscope after $24 \mathrm{~h}(A, C)$, and the inhibitory rate was calculated $(B, D)$. Furthermore, the cells transfected with miR-27b mimics or smiR-27b were transferred to the upper Transwell chamber precoated with Matrigel. The cells that invaded the lower Transwell chamber were stained with Wright-Giemsa solution, imaged as described in Materials and Methods $(E)$ and counted under a microscope. The inhibitory rate was calculated from three independent experiments $(F)$. Results represent the mean of three individual experiments; error bars represent SD. $\left.{ }^{* *}\right) P<0.01$ versus control. 

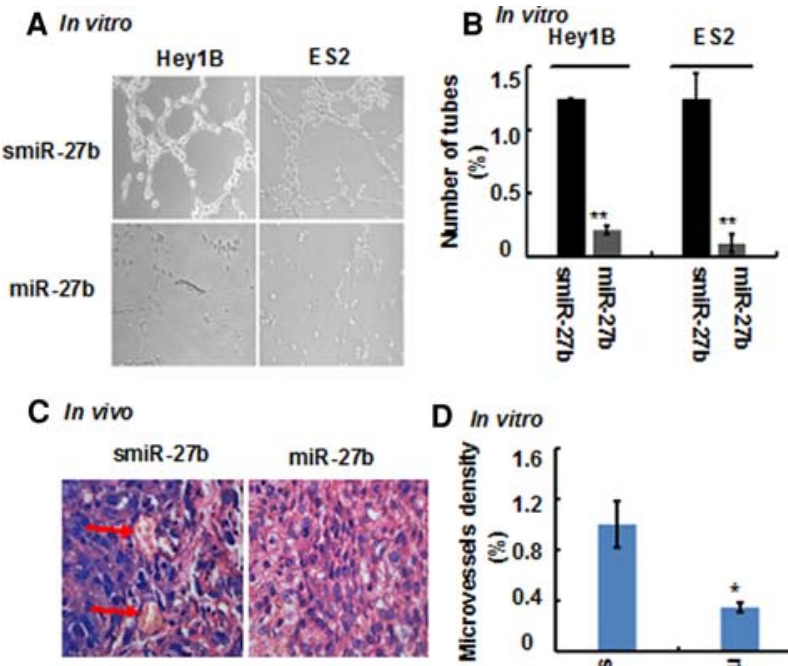

\section{In vitro}

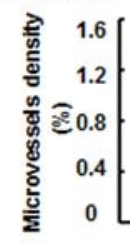

\section{E}

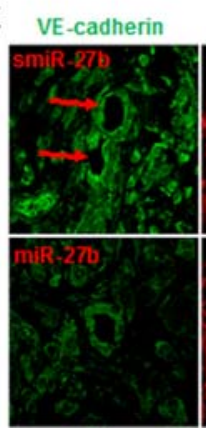

HE 4
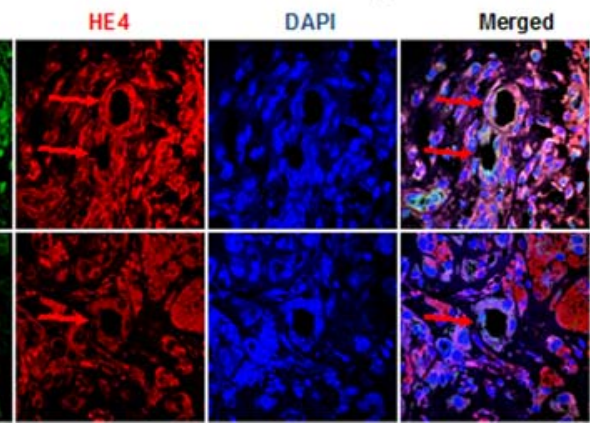

FIGURE 5. MiR-27b inhibits the formation of ovarian cancer cell-mediated capillary-like structures and vasculogenic mimicry in mice. Ovarian cancer cells were transfected with miR-27b mimics or smiR$27 \mathrm{~b}$, and capillary-like structure formation of the cells was tested on Matrigel and photographed under a light microscope $(A)$, and the tube numbers from six randomly chosen areas were counted $(B)$. In addition, ovarian cancer cell-mediated vasculogenic mimicry was detected by Matrigel plug assay. The Matrigel plugs were exercised, fixed sectioned, and stained with $\mathrm{HE}(C, 1000 \times)$, the red arrows indicate functional blood vessels with red blood cells, and the number of tumor vessels from six randomly chosen areas were analyzed $(D)$; results represent the mean of three individual experiments; error bars represent SD. $\left({ }^{*}\right) P<0.05,\left({ }^{* *}\right) P<0.01$ versus control. At the same time, the Matrigel plugs were doubly stained with both vasculogenic mimicry marker VE-cadherin and tumor marker HE4, and subjected to image under immunofluorescent microscopy $(E, 1000 \times$, green: VE-cadherin; red: HE4; blue: DAPI), and the red arrows indicate tumor cell-formed blood vessels.

cell-mediated formation of capillary-like structures in vitro and generation of functional blood vessels in mice (Fig. 6).

\section{DISCUSSION}

MiR-27b is down-regulated in various malignant tumors (Jiang et al. 2014; Takahashi et al. 2015; Zhang et al. 2015; Matsuyama et al. 2016), and the reduction of miR-27b levels in cancer is closely associated with the strong tumor cell pro-

liferation, malignant progression, and poor prognosis of the cancer patients (Goto et al. 2014; Takahashi et al. 2015; Matsuyama et al. 2016). In contrast, overexpression of miR27b inhibits carcinogenesis (Tao et al. 2015; Matsuyama et al. 2016); thus, miR-27b belongs to a tumor-suppressive miRNA. Molecular mechanistic studies reveal that miR-27b targets various genes in tumor cells, including Notch ligand Dll4 (Veliceasa et al. 2015), semaphorin 6A (Urbich et al. 2012), VEGF-C (Ye et al. 2013), Sprouty-2 (Liu et al. 2015a), and PPAR $\gamma$ (Lee et al. 2012). In 2013, Young et al. (2013) reported that miR-27a binds to the $3^{\prime} \mathrm{UTR}$ of VE-cadherin mRNA to inhibit angiogenesis and vascular leaks in mice with ischemic limb injury. Most recently, Zhao et al. (2016) showed that miR-27a-3p suppresses tumor metastasis and VM via suppressing VE-cadherin expression and inhibiting EMT in hepatocellular carcinoma. However, whether miR$27 \mathrm{~b}$ is able to inhibit VM in ovarian cancer is largely unknown. In the current study, we find that miR-27b suppresses ovarian cancer cell-mediated VM by inhibiting VE-cadherin expression in the cancer cells. Our study provides new insight into the miRNA-27b-mediated suppression of intracellular $V E$-cadherin gene expression and reveals miR-27b as a new inhibitor of cancer cell-mediated VM, providing a potential new drug candidate for antitumor VM and anti-ovarian cancer therapy.

Anti-angiogenesis therapy has become an important approach in the treatment of various malignant tumors, including ovarian cancer. VEGF-targeted therapy with bevacizumab, a humanized monoclonal antibody able to diminish

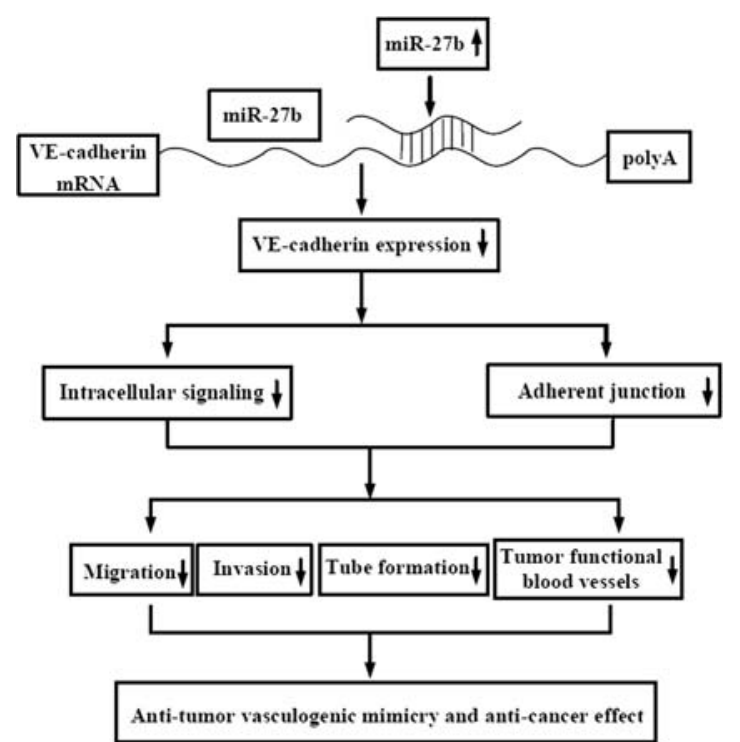

FIGURE 6. A mechanistic model for the inhibitory effect of miR-27b on ovarian cell-mediated vasculogenic mimicry. MiR-27b binds to the 3'UTR of VE-cadherin mRNA and significantly suppresses intracellular $V E$-cadherin expression in aggressive ovarian cancer Hey1B and ES2 cells, inhibits ovarian cancer cell migration and invasion, and reduces formation of ovarian cancer cell-mediated capillary-like structures in vitro and generation of functional tumor blood vessels in mice. 
endothelial cell-mediated angiogenesis, is promising in the short term of cancer patient therapy, including ovarian cancer (Cao et al. 2013b; Hou et al. 2016; Zhang et al. 2016). However, the latest meta-analysis of 12 clinical trials of VEGF-targeted anti-angiogenesis therapy in ovarian cancer patients shows that the benefit of the anti-angiogenesis therapy using a combination of bevacizumab with standard cytotoxic chemotherapy is short-lived, since it significantly increases progression-free survival (PFS) but does not significantly prolong overall survival (OS), as seen in several randomized Phase III trials (Jackson et al. 2015; Liu et al. 2015b; Yoshida et al. 2015; Al Wadi and Ghatage 2016; Monk et al. 2016), suggesting that single inhibition of endothelial cell-dominant angiogenesis is not enough to keep ovarian cancer at bay, and new strategies and therapeutics are highly desirable in order to increase the long-term survival rate of ovarian cancer patients. Accumulated evidence shows that cancer cell-mediated VM plays a critical role in the tumor malignant progression and metastasis, and VM-positive cancer patients have poor 5-yr overall survival when compared with VM-negative malignant tumor cases (Cao et al. 2013a; Wagenblast et al. 2015); hence, cancer cell-mediated VM is a sensible target for antitumor VM therapy. However, tumor VM-targeted therapeutics is absent in the clinical setting. In this study, for the first time we identified miR-27b as an effective inhibitor of ovarian cancer cell-mediated VM, furnishing a new way for anti-ovarian cancer VM therapy. The combination of antitumor VMbased therapeutics, including miR-27b, with traditional anti-angiogenic drugs may improve the efficacy of anti-ovarian cancer therapy.

Various angiogenesis- and tumor-suppressive miRNAs have been recently discovered (Sun et al. 2014; Wang et al. 2015). Among these miRNAs, miR-27b is frequently downregulated in human ovarian cancer cells and associated with malignant progression and poor prognosis of patients (Goto et al. 2014; Takahashi et al. 2015; Matsuyama et al. 2016); hence, up-regulation of endogenous miR-27b expression in cancer cells or delivery of synthesized miR-27b mimics to malignant tumor cells seems to be a new strategy for antitumor neovascularization and anti-ovarian cancer therapy. In the foreseeable future, finding the endogenous molecules and signaling pathways that are able to effectively up-regulate miR-27b expression in ovarian cancer cells will bring about antitumor vasculogenic and tumor-suppressive effects in ovarian cancer patients. On the other hand, screening and validation of exogenous agents that elevate miR-27b levels in cancer cells will provide new potential antitumor drug candidates.

\section{MATERIALS AND METHODS}

\section{Materials}

Human ovarian cancer cell line HeylB was obtained from American Type Culture Collection (ATCC) (Manassas) and ES2, SKOV3, and OVCAR3 were purchased from the Shanghai Institute of Biochemistry and Cell Biology, Chinese Academy of Sciences. MiR-27b mimic (5'-UUCACAGUGGCUAAGUUCUGC-3'), miR27b mimic negative control (5'-UUCUCCGAACGUGUCACGU TT-3'), miR-221 inhibitor (5'-GCAGAACUUAGCCACUGUG AA- $3^{\prime}$ ), and miR-27b inhibitor negative control (5'-CAGUA CUUUUGUGUAGUACAA- $3^{\prime}$ ) were purchased from Jima Biotech. The RevertAid First Strand cDNA Synthesis Kit was from Fermentas Life Sciences. The Taq DNA Polymerase was from TaKaRa Biotechnology Co., Ltd. Matrigel was from BD Biosciences. Transwell chambers were from Corning Costar. The monoclonal antibody against $\beta$-actin was obtained from Sigma-Aldrich. The anti-VE-cadherin antibody was from Abcam. Primers were synthesized by GENEWIZ, Inc. and listed in Supplemental Table 1.

\section{Cell culture}

Cells were cultured in a DMEM medium supplemented with $10 \%$ fetal bovine serum (FBS), penicillin (100 units/mL), and streptomycin $(100 \mu \mathrm{g} / \mathrm{mL})$ in a $5 \% \mathrm{CO}_{2}$ incubator at $37^{\circ} \mathrm{C}$ as previously described (Cao et al. 2013c).

\section{Reverse transcription PCR and QT-PCR}

Reverse transcription PCR (RT-PCR) and QT-PCR were performed as previously described (Bao et al. 2012; Cao et al. 2013c). In brief, total RNA was extracted from cells by TRIzol, and the cDNA was generated by reverse transcription using the RevertAid First Strand cDNA Synthesis Kit. Primer sequences for miRNA27b and U6 detection are listed in Supplemental Table 1, and the RT primer for mature miRNA27b was designed according to the method of a stem-loop RT primer (Lei et al. 2014). RT-PCR products were measured by the GelDoc XR System (Bio-Rad), and the results were analyzed using Quantity One software (Bio-Rad) (Bao et al. 2012). Real-time PCR was conducted using a LightCycler480 II RealTime PCR system (Roche Applied Science) with the SYBR-Greenbased method according to the manufacturer's instructions. Briefly, the real-time PCR was performed as follows: $7 \mu \mathrm{L} \mathrm{ddH}{ }_{2} \mathrm{O}$, $10 \mu \mathrm{L} 2 \times$ SYBR mix, $1 \mu \mathrm{L}$ forward primer, $1 \mu \mathrm{L}$ reverse primer, and $1 \mu \mathrm{L}$ cDNA templates were added to a $200 \mu \mathrm{L}$ tube. The PCR reaction consisted of an initial denaturation at $94^{\circ} \mathrm{C}$ for $10 \mathrm{~min}$, followed by denaturation at $94^{\circ} \mathrm{C}$ for $30 \mathrm{sec}$, annealing at $60^{\circ} \mathrm{C}$ for 30 sec, and extension at $72^{\circ} \mathrm{C}$ for $30 \mathrm{sec}$ each PCR cycle for a total of 45 cycles. Relative expression levels of VE-cadherin mRNA and miR-27b were analyzed by the $\Delta \Delta \mathrm{C}_{\mathrm{t}}$ method, following normalization to $\beta$-actin and U6 reported by Lei et al. (2014), respectively.

\section{Western blotting}

Cells were collected and protein lysates were prepared as we reported earlier (Cao et al. 2013c; Yu et al. 2014). Equal amounts of protein were loaded into each lane and resolved by sodium dodecyl sulfate polyacrylamide gel electrophoresis (SDS-PAGE) with Tris-glycine running buffer and transferred to nitrocellulose membranes. Membranes were blocked with 5\% nonfat milk and incubated overnight at $4^{\circ} \mathrm{C}$ with primary antibodies against $V E$-cadherin, followed by incubation with HRP-coupled secondary antibody. Blots were visualized using enhanced chemiluminescence (ECL) detection 
reagents and exposed to X-ray film, then stripped and reprobed with the anti- $\beta$-actin-HRP antibody.

\section{Tube formation assay}

The tumor cell formation of capillary structures in vitro was performed as we previously described (Cao et al. 2013c). In brief, cells were transferred to each well of a 48 -well plate containing $0.15 \mathrm{~mL}$ Matrigel matrix (without supplement of growth factors). After incubation at $37^{\circ} \mathrm{C}, 5 \% \mathrm{CO}_{2}$ for $16 \mathrm{~h}$, the tubes were photographed by a microscope, and the tubes in six randomly chosen fields were analyzed.

\section{Matrigel plug assay in mice}

Matrigel plug assay was used to evaluate blood vessel formation in mice as reported by Veliceasa et al. (2015). Briefly, $2 \times 10^{6}$ ovarian cancer ES2 cells were mixed with $0.5 \mathrm{~mL}$ Matrigel, miR-27b mimics, or random sequenced miR-27b as a negative control $(80 \mu \mathrm{g}$ per mouse), and formulated with in vivo-JetPEI (PolyPlus Transfection) in $5 \%$ glucose, according to the manufacturer's instructions. The mixture was injected subcutaneously in the median abdominal area of anesthetized nude mice and allowed to solidify. After $10 \mathrm{~d}$, the plugs were excised and snap-frozen for analysis of blood vessel formation in mice.

\section{Immunohistochemical staining}

Paraffin-embedded Matrigel plugs were cut at a thickness of $4 \mu \mathrm{m}$ and mounted on glass slides. Tissue sections were stained with hematoxylin and eosin (HE) as previously described (Cao et al. 2013c). In addition, Matrigel plugs were sectioned, deparaffinized, and blocked with normal goat serum; then the slides were stained with anti-VE-cadherin and anti-HE4 primary antibodies at $4^{\circ} \mathrm{C}$ overnight, followed by incubation with Alexa Fluor 594 goat antirabbit IgG and Alexa Fluor 488 goat anti-mouse IgG for $1 \mathrm{~h}$ at room temperature, stained with DAPI for $10 \mathrm{~min}$, and observed under an Olympus confocal microscope.

\section{VE-cadherin mRNA 3'UTR subcloning and luciferase activity assay}

A 182-bp fragment of human VE-cadherin mRNA 3'UTR (position 624-805) containing a predicted miR-27b-binding site at the position of 715-722 (UGACACUU) was synthesized (Genewiz) and subcloned into a psiCHECK-2 vector to create a wild type psiCHECK-2-VE-cadherin mRNA $3^{\prime}$ UTR. Comparably, 8 bp at VE-cadherin 3'UTR (position 715-722) were mutated, and the mutated fragment (CAGTCAGG) was also directly synthesized (Genewiz) and subcloned into the psiCHECK-2 vector to generate the respective psiCHECK-2-VE-cadherin mRNA 3'UTR-mutant. Then, ovarian cell ES2 cells were cotransfected with $50 \mathrm{ng}$ of the above-described luciferase-VE-cadherin mRNA $3^{\prime} \mathrm{UTR}$ constructs and with $20 \mathrm{nM}$ of either miR-27b mimic or scrambled miR-27b together with Renilla luciferase construct, respectively, using Lipofectamine 2000 (Invitrogen). Forty-eight hours later, the cells were harvested and the luciferase and Renilla luciferase activities were analyzed using the Dual-Luciferase Reporter Assay System (Promega).

\section{Cell migration assay}

The wound healing assay was used to evaluate cell migration in this study as we previously described (Bao et al. 2012; Liu et al. 2015c). Briefly, ovarian cancer cells transfected with miR-27b mimics or scrambled miR-27b were first cultured in six-well plates to confluence, and then scraped with the fine end of a pipette tip and washed three times with PBS to remove detached cells (time 0 ). The cells were incubated with the complete medium for 36 h. Cell migration was photographed using an Olympus FSX-100 microscope.

\section{Cell invasion assay}

The tumor cell invasion assay was performed using Transwell chambers as reported previously (Bao et al. 2012; Liu et al. 2015c). Briefly, cells transfected with miR-27b mimics or scrambled miR-27b were suspended with serum-free medium. The cells $\left(1 \times 10^{5}\right.$ per well $)$ were added to the upper chamber precoated with $50 \mu \mathrm{L}$ of Matrigel for $0.5 \mathrm{~h}$. Meanwhile, $0.5 \mathrm{~mL}$ of 10\% FBS-DMEM complete medium was added to the lower chamber. After $24 \mathrm{~h}$, the invaded cells in the lower chamber were fixed, stained with WrightGiemsa solution, and then photographed.

\section{Statistical analysis}

The data in this study are represented as mean \pm SD. Differences between the groups were assessed by one-way ANOVA using SPSS 16.0. Comparisons were made between treated and untreated control groups, and the significance of differences is indicated as $\left(^{*}\right)$ $P<0.05$ and $(* *) P<0.01$.

\section{SUPPLEMENTAL MATERIAL}

Supplemental material is available for this article.

\section{ACKNOWLEDGMENTS}

This study was supported by grants from the National Natural Science Foundation of China (grant nos. 81372376 and 81572257 ), a project funded by the priority academic program development of Jiangsu Higher Education Institutions (PAPD), 2011 Collaborative Innovation Center of Hematology, Soochow University, and Jiangsu Key Laboratory of Preventive and Translational Medicine for Geriatric Diseases, Key Laboratory of Stem Cells and Biomedical Materials of Jiangsu Province and Chinese Ministry of Science and Technology, Natural Science Funds of Jiangsu Colleges and Universities (no. 16KJB310015), Suzhou City Scientific Research Funds (no. SYS201418), and Natural Science Funds of Soochow University (no. SDY2014A22).

Received October 15, 2016; accepted April 1, 2017. 


\section{REFERENCES}

Al Wadi K, Ghatage P. 2016. Efficacy of trebananib (AMG 386) in treating epithelial ovarian cancer. Expert Opin Pharmacother 17: 853-860.

Baeten CI, Hillen F, Pauwels P, de Bruine AP, Baeten CG. 2009. Prognostic role of vasculogenic mimicry in colorectal cancer. Dis Colon Rectum 52: 2028-2035.

Bao M, Cao Z, Yu D, Fu S, Zhang G, Yang P, Pan Y, Yang B, Han H, Zhou Q. 2012. Columbamine suppresses the proliferation and neovascularization of metastatic osteosarcoma U2OS cells with low cytotoxicity. Toxicol Lett 215: 174-180.

Cao Z, Bao M, Miele L, Sarkar FH, Wang Z, Zhou Q. 2013a. Tumour vasculogenic mimicry is associated with poor prognosis of human cancer patients: a systemic review and meta-analysis. Eur J Cancer 49: 3914-3923.

Cao Z, Shang B, Zhang G, Miele L, Sarkar FH, Wang Z, Zhou Q. 2013b. Tumor cell-mediated neovascularization and lymphangiogenesis contrive tumor progression and cancer metastasis. Biochim Biophys Acta 1836: 273-286.

Cao Z, Yu D, Fu S, Zhang G, Pan Y, Bao M, Tu J, Shang B, Guo P, Yang P, et al. 2013c. Lycorine hydrochloride selectively inhibits human ovarian cancer cell proliferation and tumor neovascularization with very low toxicity. Toxicol Lett 218: 174-185.

Carmeliet P, Jain RK. 2011. Molecular mechanisms and clinical applications of angiogenesis. Nature. 473: 298-307.

da Costa AA, Valadares CV, Mantoan H, Saito A, Salvadori MM, Guimaraes AP, Sanches SM, Achatz MI, Baiocchi G. 2016. The value of secondary cytoreductive surgery in recurrent ovarian cancer and application of a prognostic score. Int J Gynecol Cancer 26: 449-455.

Davidson B. 2016. Recently identified drug resistance biomarkers in ovarian cancer. Expert Rev Mol Diagn. 16: 569-578.

Du J, Sun B, Zhao X, Gu Q, Dong X, Mo J, Sun T, Wang J, Sun R, Liu Y. 2014. Hypoxia promotes vasculogenic mimicry formation by inducing epithelial-mesenchymal transition in ovarian carcinoma. Gynecol Oncol 133: 575-583.

Folkman J. 1971. Tumor angiogenesis: therapeutic implications. N Engl J Med 285: 1182-1186.

Fry SA, Robertson CE, Swann R, Dwek MV. 2016. Cadherin-5: a biomarker for metastatic breast cancer with optimum efficacy in oestrogen receptor-positive breast cancers with vascular invasion. $\mathrm{Br} J$ Cancer 114: 1019-1026.

Goto Y, Kojima S, Nishikawa R, Enokida H, Chiyomaru T, Kinoshita T, Nakagawa M, Naya Y, Ichikawa T, Seki N. 2014. The microRNA$23 \mathrm{~b} / 27 \mathrm{~b} / 24-1$ cluster is a disease progression marker and tumor suppressor in prostate cancer. Oncotarget 5: 7748-7759.

Hendrix MJ, Seftor EA, Meltzer PS, Gardner LM, Hess AR, Kirschmann DA, Schatteman GC, Seftor RE. 2001. Expression and functional significance of VE-cadherin in aggressive human melanoma cells: role in vasculogenic mimicry. Proc Natl Acad Sci 98: 8018-8023.

Hendrix MJ, Seftor EA, Seftor RE, Chao JT, Chien DS, Chu YW. 2016. Tumor cell vascular mimicry: novel targeting opportunity in melanoma. Pharmacol Ther 159: 83-92.

Hou MM, Wang Z, Janku F, Piha-Paul S, Naing A, Hong D, Westin S, Coleman RL, Sood AK, Tsimberidou AM, et al. 2016. Continuous anti-angiogenic therapy after tumor progression in patients with recurrent high-grade epithelial ovarian cancer: phase I trial experience. Oncotarget 7: 35132-35143.

Jackson AL, Eisenhauer EL, Herzog TJ. 2015. Emerging therapies: angiogenesis inhibitors for ovarian cancer. Expert Opin Emerg Drugs 20: 331-346.

Jiang J, Lv X, Fan L, Huang G, Zhan Y, Wang M, Lu H. 2014. MicroRNA-27b suppresses growth and invasion of NSCLC cells by targeting Sp1. Tumour Biol 35: 10019-10023.

Khorshidi A, Dhaliwal P, Yang BB. 2016. Noncoding RNAs in tumor angiogenesis. Adv Exp Med Biol 927: 217-241.

Lee JJ, Drakaki A, Iliopoulos D, Struhl K. 2012. MiR-27b targets PPAR $\gamma$ to inhibit growth, tumor progression and the inflammatory response in neuroblastoma cells. Oncogene 31: 3818-3825.
Lei Z, Xu G, Wang L, Yang H, Liu X, Zhao J, Zhang HT. 2014. MiR-142$3 p$ represses TGF- $\beta$-induced growth inhibition through repression of TGF $\beta R 1$ in non-small cell lung cancer. FASEB J 28: 2696-2704.

Li M, Gu Y, Zhang Z, Zhang S, Zhang D, Saleem AF, Zhao X, Sun B. 2010. Vasculogenic mimicry: a new prognostic sign of gastric adenocarcinoma. Pathol Oncol Res 16: 259-266.

Liu C, Liang S, Xiao S, Lin Q, Chen X, Wu Y, Fu J. 2015a. MicroRNA27b inhibits Spry2 expression and promotes cell invasion in glioma U251 cells. Oncol Lett 9: 1393-1397.

Liu FW, Cripe J, Tewari KS. 2015b. Anti-angiogenesis therapy in gynecologic malignancies. Oncology (Williston Park) 29: 350-360.

Liu W, Meng M, Zhang B, Du L, Pan Y, Yang P, Gu Z, Zhou Q, Cao Z. 2015c. Dehydroeffusol effectively inhibits human gastric cancer cellmediated vasculogenic mimicry with low toxicity. Toxicol Appl Pharmacol 287: 98-110.

Mao XG, Xue XY, Wang L, Zhang X, Yan M, Tu YY, Lin W, Jiang XF, Ren HG, Zhang W, et al. 2013. CDH5 is specifically activated in glioblastoma stemlike cells and contributes to vasculogenic mimicry induced by hypoxia. Neuro Oncol 15: 865-879.

Matsuyama R, Okuzaki D, Okada M, Oneyama C. 2016. MicroRNA-27b suppresses tumor progression by regulating ARFGEF1 and focal adhesion signaling. Cancer Sci 107: 28-35.

May C, Doody JF, Abdullah R, Balderes P, Xu X, Chen CP, Zhu Z, Shapiro L, Kussie P, Hicklin DJ, et al. 2005. Identification of a transiently exposed VE-cadherin epitope that allows for specific targeting of an antibody to the tumor neovasculature. Blood 105: 4337-4344.

Monk BJ, Minion LE, Coleman RL. 2016. Anti-angiogenic agents in ovarian cancer: past, present, and future. Ann Oncol 27(Suppl 1): i33-i39.

Ren K, Yao N, Wang G, Tian L, Ma J, Shi X, Zhang L, Zhang J, Zhou X, Zhou G, et al. 2014. Vasculogenic mimicry: a new prognostic sign of human osteosarcoma. Hum Pathol 45: 2120-2129.

Seftor RE, Hess AR, Seftor EA, Kirschmann DA, Hardy KM, Margaryan NV, Hendrix MJ. 2012. Tumor cell vasculogenic mimicry: from controversy to therapeutic promise. Am J Pathol 181: $1115-1125$.

Suh-Burgmann E, Kinney W. 2016. The value of ultrasound monitoring of adnexal masses for early detection of ovarian cancer. Front Oncol 6: 25.

Sun Q, Zou X, Zhang T, Shen J, Yin Y, Xiang J. 2014. The role of miR$200 \mathrm{a}$ in vasculogenic mimicry and its clinical significance in ovarian cancer. Gynecol Oncol 132: 730-738.

Takahashi RU, Miyazaki H, Takeshita F, Yamamoto Y, Minoura K, Ono M, Kodaira M, Tamura K, Mori M, Ochiya T. 2015. Loss of microRNA-27b contributes to breast cancer stem cell generation by activating ENPP1. Nat Commun 6: 7318 .

Tang J, Wang J, Fan L, Li X, Liu N, Luo W, Wang J, Wang Y, Wang Y. 2016. cRGD inhibits vasculogenic mimicry formation by down-regulating uPA expression and reducing EMT in ovarian cancer. Oncotarget 7: 24050-24062.

Tao J, Zhi X, Zhang X, Fu M, Huang H, Fan Y, Guan W, Zou C. 2015. miR-27b-3p suppresses cell proliferation through targeting receptor tyrosine kinase like orphan receptor 1 in gastric cancer. J Exp Clin Cancer Res 34: 139.

Urbich C, Kaluza D, Fromel T, Knau A, Bennewitz K, Boon RA, Bonauer A, Doebele C, Boeckel JN, Hergenreider E, et al. 2012. MicroRNA-27a/b controls endothelial cell repulsion and angiogenesis by targeting semaphorin 6A. Blood 119: 1607-1616.

Veliceasa D, Biyashev D, Qin G, Misener S, Mackie AR, Kishore R, Volpert OV. 2015. Therapeutic manipulation of angiogenesis with miR-27b. Vasc Cell 7: 6.

Wagenblast E, Soto M, Gutierrez-Angel S, Hartl CA, Gable AL, Maceli AR, Erard N, Williams AM, Kim SY, Dickopf S, et al. 2015. A model of breast cancer heterogeneity reveals vascular mimicry as a driver of metastasis. Nature 520: 358-362.

Wang W, Zhang E, Lin C. 2015. MicroRNAs in tumor angiogenesis. Life Sci 136: 28-35.

Wang Z, Xu L, Hu Y, Huang Y, Zhang Y, Zheng X, Wang S, Wang Y, Yu Y, Zhang M, et al. 2016. miRNA let-7b modulates macrophage 
polarization and enhances tumor-associated macrophages to promote angiogenesis and mobility in prostate cancer. Sci Rep 6: 25602.

Wu S, Yu L, Cheng Z, Song W, Zhou L, Tao Y. 2012. Expression of maspin in non-small cell lung cancer and its relationship to vasculogenic mimicry. J Huazhong Univ Sci Technol Med Sci 32: 346-352.

Xu XD, Yang L, Zheng LY, Pan YY, Cao ZF, Zhang ZQ, Zhou QS, Yang B, Cao C. 2014. Suberoylanilide hydroxamic acid, an inhibitor of histone deacetylase, suppresses vasculogenic mimicry and proliferation of highly aggressive pancreatic cancer PaTu8988 cells. BMC Cancer 14: 373.

Yang WJ, Yang DD, Na S, Sandusky GE, Zhang Q, Zhao G. 2005. Dicer is required for embryonic angiogenesis during mouse development. J Biol Chem 280: 9330-9335.

Ye J, Wu X, Wu D, Wu P, Ni C, Zhang Z, Chen Z, Qiu F, Xu J, Huang J. 2013. miRNA-27b targets vascular endothelial growth factor $C$ to inhibit tumor progression and angiogenesis in colorectal cancer. PLoS One 8: e60687.

Yoshida H, Yabuno A, Fujiwara K. 2015. Critical appraisal of bevacizumab in the treatment of ovarian cancer. Drug Des Devel Ther 9: 2351-2358.
Young JA, Ting KK, Li J, Moller T, Dunn L, Lu Y, Moses J, PradoLourenco L, Khachigian LM, Ng M, et al. 2013. Regulation of vascular leak and recovery from ischemic injury by general and VE-cadherin-restricted miRNA antagonists of miR-27. Blood 122: 2911-2919.

Yu D, Fu S, Cao Z, Bao M, Zhang G, Pan Y, Liu W, Zhou Q. 2014. Unraveling the novel anti-osteosarcoma function of coptisine and its mechanisms. Toxicol Lett 226: 328-336.

Zhang S, Liu F, Mao X, Huang J, Yang J, Yin X, Wu L, Zheng L, Wang Q. 2015. Elevation of miR-27b by HPV16 E7 inhibits PPAR $\gamma$ expression and promotes proliferation and invasion in cervical carcinoma cells. Int J Oncol 47: 1759-1766.

Zhang W, Shen Z, Luo H, Hu X, Zheng L, Zhu X. 2016. The benefits and side effects of bevacizumab for the treatment of recurrent ovarian cancer. Curr Drug Targets.

Zhao N, Sun H, Sun B, Zhu D, Zhao X, Wang Y, Gu Q, Dong X, Liu F, Zhang Y, et al. 2016. miR-27a-3p suppresses tumor metastasis and VM by down-regulating VE-cadherin expression and inhibiting EMT: an essential role for Twist-1 in HCC. Sci Rep 6: 23091. 

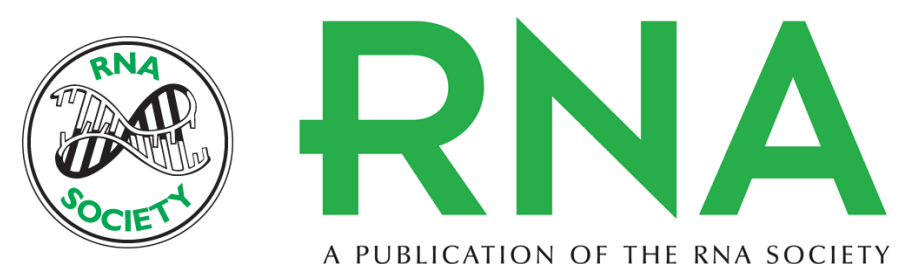

A PUBLICATION OF THE RNA SOCIETY

\section{MicroRNA-27b functions as a new inhibitor of ovarian cancer-mediated vasculogenic mimicry through suppression of VE-cadherin expression}

Wenming Liu, Chunping Lv, Bin Zhang, et al.

RNA 2017 23: 1019-1027 originally published online April 10, 2017

Access the most recent version at doi:10.1261/rna.059592.116

Supplemental Material

References

Creative Commons License

Email Alerting Service
http://rnajournal.cshlp.org/content/suppl/2017/04/10/rna.059592.116.DC1

This article cites 50 articles, 6 of which can be accessed free at: http://rnajournal.cshlp.org/content/23/7/1019.full.html\#ref-list-1

This article is distributed exclusively by the RNA Society for the first 12 months after the full-issue publication date (see http://rnajournal.cshlp.org/site/misc/terms.xhtml). After 12 months, it is available under a Creative Commons License (Attribution-NonCommercial 4.0 International), as described at http://creativecommons.org/licenses/by-nc/4.0/.

Receive free email alerts when new articles cite this article - sign up in the box at the top right corner of the article or click here.

\section{|||||||| Providing Precise Solutions for} your research.

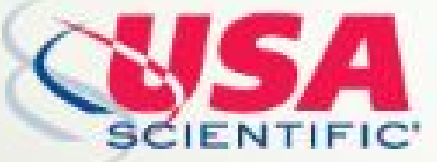

To subscribe to RNA go to:

http://rnajournal.cshlp.org/subscriptions

C 2017 Liu et al.; Published by Cold Spring Harbor Laboratory Press for the RNA Society 